\title{
Cool it or not but based on what?
}

\author{
B. Yildiz $^{1} \cdot$ M. Tez ${ }^{1}$
}

Received: 21 February 2017 / Accepted: 12 September 2017 / Published online: 21 September 2017

(C) Springer-Verlag GmbH Germany 2017

\section{Dear Editor,}

We read with great interest the article titled "Admission after the gold interval in acute calculous cholecystitis: Should we really cool it off?" by Bozkurt et al. [1]. The authors retrospectively reviewed and compared treatment outcomes of patients with acute cholecystitis who had early or late cholecystectomy. How did the authors identify which patients to send to surgery? Do they have a standard algorithm? The methodology of directing patients in each treatment arm is poorly defined.

The authors are not mentioning Tokyo guidelines [2] at all which actually outlines and standardizes management of acute cholecystitis in a step-by-step manner. The latest update of Tokyo guidelines is the 13th version and it evaluates systemic inflammation, cholestasis, imaging findings. Sensitivity and specificity of the 13th version reaches 91.8 and $77.7 \%$ [3]. Authors could also have analysed if their previous management scheme would resulted differently if they had followed Tokyo guidelines. This would be a valuable external validation of the Tokyo guidelines in a different population.

\section{Compliance with ethical standards}

Conflict of interest Mesut Tez and Baris Yildiz declare that they have no conflict of interest.

Ethical approval This work does not involve human or animal participants.

Informed consent Informed consent is not needed for this work.

\section{References}

1. Bozkurt MA, Gönenç M, Peker KD, Yırgın H, Alış H. Admission after the gold interval in acute calculous cholecystitis: Should we really cool it off?. Eur J Trauma Emerg Surg. 2017;43(1):73-7. doi:10.1007/s00068-015-0617-6.

2. Takada T, Strasberg SM, Solomkin JS, Pitt HA, Gomi H, Yoshida M, et al. TG13: Updated Tokyo guidelines for the management of acute cholangitis and cholecystitis. J Hepatobiliary Pancreat Sci. 2013;20(1):1-7. doi:10.1007/s00534-012-0566-y.

3. Kiriyama S, Takada T, Strasberg SM, Solomkin JS, Mayumi T, Pitt HA. TG13 guidelines for diagnosis and severity grading of acute cholangitis (with videos). J Hepatobiliary Pancreat Sci. 2013;20:24-34.

A reply to this Letter to the Editor can be read here: doi:10.1007/ s00068-017-0846-y.

This Letter to the Editor refers to the article available at doi:10.1007/s00068-015-0617-6.

B. Yildiz

baris104@yahoo.com

1 Ankara Numune Teaching Hospital General Surgery,

Sihhiye, Ankara, Turkey 